\title{
Functional donor-site morbidity after soleus muscle-flap procedure in the treatment of lower limb severe injuries
}

\section{Funktionsstörungen an der Entnahmestelle nach Behandlung schwerer Verletzungen der unteren Extremität durch Musculus-soleus-Lappenplastik}

Authors

Michele Riccio ${ }^{1}$, Nicola Zingaretti ${ }^{2}$, Federica Verdini ${ }^{3}$, Andrea Marchesini ${ }^{1}$, Francesco De Francesco ${ }^{1}$, Pier Camillo Parodi²

Institutes

1 AOU Ospedali Riuniti di Ancona, Marche Polytechnic University, Ancona, Italy Department of Reconstructive Surgery and Hand Surgery

2 Academic Hospital of Udine, Department of Medical Area (DAME) Clinic of Plastic Surgery

3 Marche Polytechnic University, Ancona, Italy Department of Informatics Engineering

Key words

EMG, gait, walking speed, soleus flap, heel rise, limb saving surgery

Schlüsselwörter

Gang, Gehgeschwindigkeit, Soleuslappen, Gliedmaßen-erhaltende Chirurgie

submitted 29.01.2019

accepted 24.06.2019

Bibliograpy

DOI https://doi.org/10.1055/a-0972-1247

Handchir Mikrochir Plast Chir 2019; 51: 453-463

(c) Georg Thieme Verlag KG Stuttgart · New York

ISSN 0722-1819

Correspondence Address

M.D Nicola Zingaretti

Academic Hospital of Udine, Department of Medical Area

(DAME) Clinic of Plastic Surgery

Piazzale Santa Maria della Misericordia 15

33100 Udine

Tel.: +393391190024

Fax: +390432552510

E-Mail: zingarettin@gmail.com

\section{ABSTRACT}

Background The gastrocnemius and soleus muscle flaps are the most commonly used transfer flaps to treat lower limb severe lesions. The use of the muscle as coverage tissuemay incur in functionality loss and motor control deficits. The aim of this study is to assess whether functional deficits are present during gait, posture and heel rise test (HRT).
Method From 2008-2013 we treated 9 patients suffering from complex injury of the lower third of the leg (Gustilo III B). A population of 9 patients (group A) was examined after reconstruction with a soleus muscle flap. The results were compared with a control population (group B: 9 patients). Each patient performed at least 3 gait tests at a fast pace, 2 posture tests and 2 HRT on an inclined plane.

Results Gait parameters for group A: Spatio-temporal parameters such as step length, cadence were reduced compared to the homolateral leg $(p<0.05)$. The initial double support phase was shorter in relation to the final phase and the first peak in the vertical ground reaction component was reduced compared to the contralateral leg.

Posture for the group A: the mediolateral excursion (during open- and closed-eyes test) and the related mean velocity (in the open-eyes test) were significantly lower compared to the control group $(p<0.05)$.

HRT for group A: the number of rises and relative height and angular excursion were reduced in the operated leg in relation to the control group $(p<0.05)$ and to the contralateral leg.

Conclusion The patients treated with the soleus muscle used as tissue defect coverage completely recovered the ability to walk but showed some deficits in kinetic parameters during the body weight-loading phase. During gait prolonged muscle activity compared to controls was observed. The absence of soleus (group A) revealed no significant alterations in postural control. However, the HRT remained the most relevant test to measure patients' performance when treated with soleus flap in relation to the control group.

\section{ZUSAMMENFASSUNG}

Hintergrund Der Musculus-gastrocnemius-Lappen und der Musculus-soleus-Lappen sind die am häufigsten verwendeten Transferlappen zur Behandlung schwerer Verletzungen der unteren Extremität. Die Verwendung des Muskels zur Defektdeckung kann zu einem Funktionsverlust und zu Defiziten der motorischen Kontrolle führen. Ziel dieser Studie war es, zu beurteilen, ob bei Gang- und Haltungstests und beim Zehenspitzenstand („Heel-Rise-Test“, HRT) Funktionsdefizite vorhanden sind.

Methode Von 2008-2013 behandelten wir 9 Patienten mit komplexen Verletzungen des unteren Beindrittels (Gustilo III B). 
Eine Population von 9 Patienten (Gruppe A) wurde nach Rekonstruktion mit einem Musculus-soleus-Lappen untersucht. Die Ergebnisse wurden mit einer Kontrollpopulation (Gruppe B: 9 Patienten) verglichen. Jeder Patient führte mindestens 3 Gangtests in schnellem Tempo, 2 Haltungstests und 2 HRTs auf schräger Ebene durch.

Ergebnisse Gangparameter in Gruppe A: Räumlich-zeitliche Parameter wie Schrittlänge und Schrittfrequenz waren im Vergleich zum homolateralen Bein reduziert $(p<0,05)$. Die initiale Double-Support-Phase war in Relation zur Endphase kürzer und der erste Peak bei der vertikalen Bodenreaktionskraft war im Vergleich zum kontralateralen Bein reduziert.

Haltungsparameter in Gruppe A: Die mediolaterale Exkursion (beim Test mit offenen und geschlossenen Augen) und die diesbezügliche mittlere Geschwindigkeit (im Test mit offenen Augen) waren deutlich niedriger als in der Kontrollgruppe $(p<0,05)$.
HRT in Gruppe A: Die Zahl der Anhebungen, die relative Höhe und die anguläre Exkursion waren im operierten Bein im Vergleich zur Kontrollgruppe $(p<0,05)$ und zum kontralateralen Bein reduziert.

Schlussfolgerung Die Patienten, die durch Gewebedefektdeckung mithilfe des M. soleus behandelt wurden, erlangten ihre Gehfähigkeit vollständig zurück, zeigten aber einige Defizite bei kinetischen Parametern während der Gewichtsbelastungsphase des Körpers. Beim Gehen wurde im Vergleich zur Kontrollgruppe eine verlängerte Muskelaktivität beobachtet. Das Fehlen des M. soleus (Gruppe A) führte zu keinen signifikanten Veränderungen bei der Haltungskontrolle. Der HRT hat jedoch nach wie vor die größte Relevanz in der Leistungsmessung bei Patienten, die mit einem Soleuslappen behandelt wurden, im Vergleich zur Kontrollgruppe.

\section{Introduction}

Complex limb injuries due to high kinetic energy crushes, are characterised by an extensive loss of soft tissue and bone substance related to type III of the Gustilo-Anderson classification [1, 2, 3] and may be associated with vascular injury.

These cases require coordination between the peripheral vascular and micro-surgical team and the orthopaedist to obtain a rapid and accurate diagnosis of vascularization, and to plan adequate wound care, and revascularization [4, 5].

Literature has described treatment "guidelines" regarding severe lesions of the lower limbs, with aggressive debridement of devitalised and contaminated tissue to reduce the rate of nonunion, osteomyelitis and amputation [6, 7] as well as the use of free flap transfer, within 24-72 hours [8].

Recently, new priority has been given to protecting the "zone of injury" from bacterial contamination, followed by reconstruction which will avoid flap failure caused by microvascular thrombosis [9].

We propose three steps to treat similar injuries affecting the medium-lower third of the leg:

1. aggressive early multiple debridement. In case of bone substance loss, an external fixator is applied, and the wound is adequately prepared using vacuum assisted closure therapy and/or hyperbaric oxygen therapy, in combination with specific antibiotic treatment and antibiogram, to prevent multi-resistant bacteria infection [7].

2. After 5-10 days, following multiple negative culture tests, an antibiotic-loaded cement spacer is applied between the stumps and an island medial soleus flap is placed as coverage.

3. After 2 months, in the absence of infection, a vascularised fibula is used to reconstruct the tibia following removal of the spacer.

Our investigations showed the island soleus muscle flap as a valuable tool to ensure coverage of a temporary antibiotic-loaded cement spacer and in definitive reconstruction with vascularised bone. This flap is simpler to use compared to a free flap and may be transferred with a reliable pedicle with satisfactory cosmetic outcome of the donor site. Adequate coverage of the soft-tissue and bone defect after debridement may be ensured due to optimal tissue vascularisation, removing dead space, improving vascularity and enhancing leukocyte function [7, 9], as well as avoiding the risk of vascular steal syndrome when the anterior tibial artery is damaged. However, the Soleus muscle may not be available due to high energy trauma or subsequent infection and may cause further motor function loss to an existing injured lower limb [6]. In this case, the Latissimus Dorsi free flap may be used.

The soleus muscle, along with the gastrocnemius muscle, is part of the triceps surae and is the most important extensor muscle of the foot, intrinsic to plantar extension. All the movements that involve extension, of either the ankle or the knee, such as climbing or running, involve the joint participation of the gastrocnemius with the soleus muscle. The triceps surae offers maximum potential when, the ankle is bent, and the knee extended, contracting to extend the ankle as in the last phase of walking (propulsive phase).

In posture, the soleus plays a fundamental role as a stabiliser, with restricted adjustments in the calf muscles. Histological analysis shows the soleus is mainly made up of slow contraction fibres (type I), which intervene in activities that require greater resistance but slower response times.

In literature little is reported regarding the functional recovery of the limb following reconstruction with a soleus muscle flap. In 2001, Kramers-de Quervain et al. examined 2 patients treated with a soleus muscle flap and 3 patients with a gastrocnemius muscle flap, during walking at normal speed and at fast speed on an inclined ramp [10]. Kinematic and kinetic analysis revealed the absence of deficit during walking at self-selected speed, and the presence of deficit during the propulsion phase of gait at fast speed, on an inclined ramp.

In the light of these results, the aim of this study was to assess whether the interruption of the soleus muscle, used as a covering 

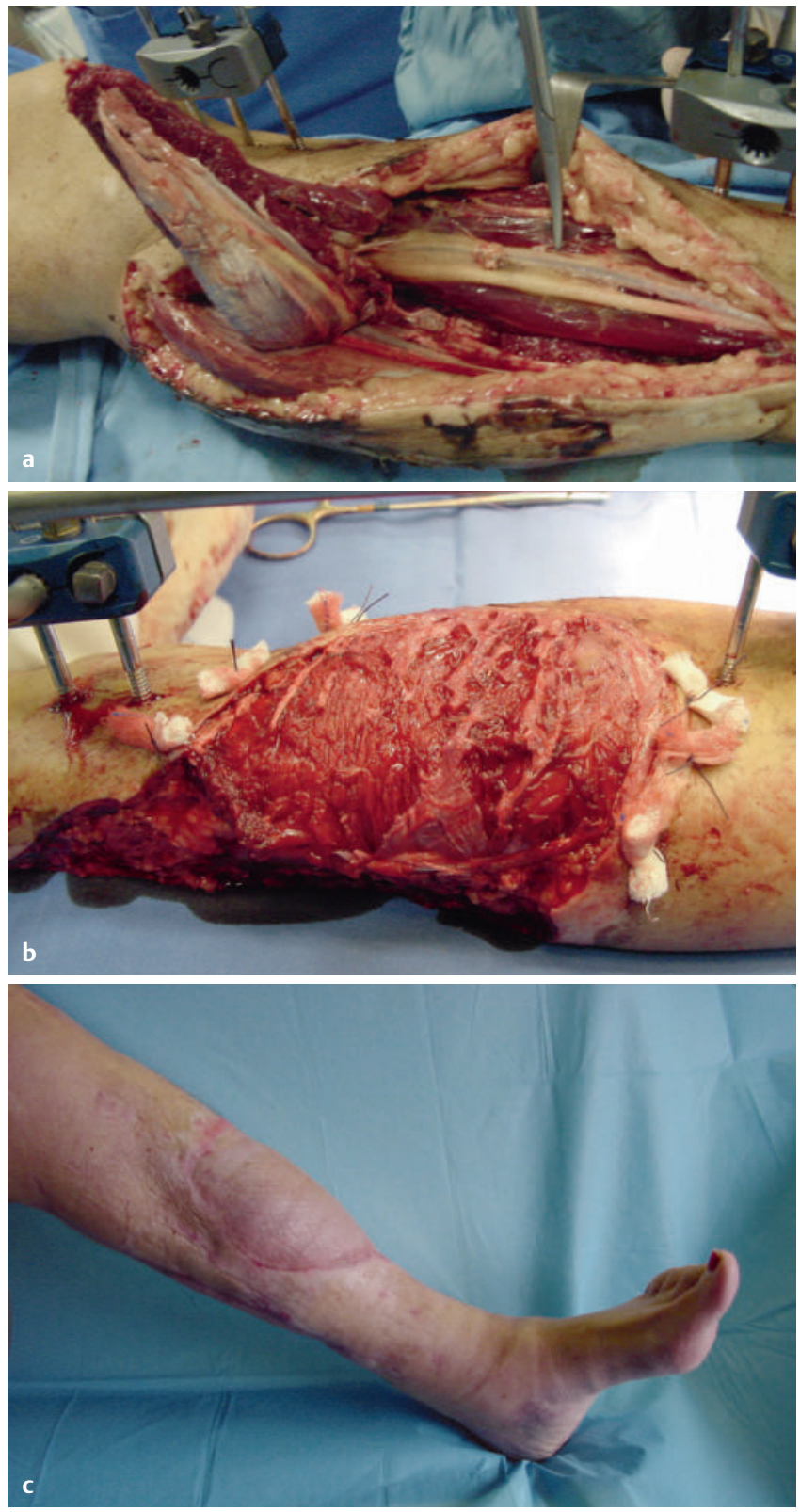

- Fig. 1 a Distal tibial defect with exposed bone from a motor vehicle accident; $\mathbf{b}$ the soleus muscle has been transposed and the split-thickness skin graft is being positioned to cover the wound (we can scoring the epimysium of the soleus muscle to extend into the distal tibia defect); c patient 1 year after soleus muscle transposition and skin grafting.

flap, caused alterations of gait and posture. We, therefore examined and reported subjects during fast-speed walking and during posture with eyes open and closed.

Moreover, to investigate deficit due to the interruption of soleus muscle, authors required the subjects to perform a heel rise test on an inclined ramp to analyse subject behaviour during a motor task commonly used to test functionality and efficiency of the triceps surae.

The patients selected for this retrospective study presented similar lesion type and identical sequelae. The patients had undergone treatment with the same surgeons over a given period.
- Table 1 Data of patients.

\begin{tabular}{|l|l|l|l|l|l|}
\hline Groups & $\begin{array}{l}\mathbf{N}^{\circ} \text { of } \\
\text { patients }\end{array}$ & $\begin{array}{l}\text { Sex } \\
\text { (F/M) }\end{array}$ & $\begin{array}{l}\text { Age } \\
\text { (Mean) }\end{array}$ & $\begin{array}{l}\text { Weight } \\
\text { (Mean, } \\
\text { kg) }\end{array}$ & $\begin{array}{l}\text { Height } \\
\text { (Mean, } \\
\mathbf{c m})\end{array}$ \\
\hline Group A & 9 & $1 / 8$ & 45 & 83 & 172 \\
\hline Group B & 9 & $2 / 7$ & 39 & 73 & 177 \\
\hline
\end{tabular}

\section{Operative Technique}

The patients who underwent reconstruction with the island soleus muscle flap were treated with the same surgical procedure including three phases: aggressive early multiple debridement, coverage of temporary antibiotic-loaded cement spacer with an island medial soleus flap, and definitive bone reconstruction using a vascularised free fibula flap.

In the first phase of surgery, the lesion was cleansed by plastic surgeons, operating on the skin, the soft tissues and the bone. The orthopaedic surgeons stabilised the bone by external fixation.

In the second phase, under pneumatic tourniquet control, an antibiotic-loaded cement spacer was applied ( $\vee$ Fig. $1 \mathbf{a}$ ), then the soleus muscle was dissected medially, arising the entire soleus and its distal tendon from the gastrocnemius muscle. The distal part of the whole soleus is entirely mobile and may rotate to, reach any defect on the distal third leg ( $\triangleright \mathbf{F i g} . \mathbf{1 b}$ ). The width of the flap may be increased by multiple transverse incisions through the epimysium of the muscle, allowing the coverage of extensive substance loss.

The recipient and/or donor site over suction drains were closed as a routine procedure.

Skin grafting was performed on all flaps at a period of 7-10 days following flap coverage to promote complete recovery ( $\triangleright$ Fig. $1 c$ ).

Rotation of skin and fascia elevated during muscle harvest often decreased the area of exposed muscle requiring skin graft coverage.

After 2 months, patients in Group A underwent free fibula flap tibia reconstruction after spacer removal.

\section{Materials and Methods}

From 2008-2013, 9 patients, suffering from severe large lesions of the skin and soft tissue of the limbs, with exposure of bone as a consequence of serious injuries (type III B of Gustilo-Anderson classification) underwent reconstruction with a soleus muscle flap (Group A). For this study, 9 healthy subjects comparable with respect to age, weight and sex were selected as a control population (Group B).

The patients covered a wide age range considering the unpredictable traumatic pattern and the absence of pathological causes $(\triangleright$ Tab. 1$)$.

The defective area of soft tissues after debridement was $7.2 \mathrm{~cm} \times$ $6.4 \mathrm{~cm}$ to $12.6 \mathrm{~cm} \times 15.3 \mathrm{~cm}$ in size, with an average area of $9.6 \mathrm{~cm} \times$ $13.1 \mathrm{~cm}$. The bone defects were $5.4 \mathrm{~cm}$ to $10.5 \mathrm{~cm}$ in size. We included patients who had gained complete functional recovery from the initial lesion with no concomitant locomotor pathology, and at least 2 years since last surgery. The patients presented similar le- 
- Table 2 Mean and standard deviation (SD) values of spatio-temporal parameters during gait for two group of subjects (A: treated with soleus flap; B: control group). ${ }^{*}$ Statistical differences (K-S test. $\left.\mathrm{p}<0.05\right)$ between parameters of A and B group.

\begin{tabular}{|c|c|c|c|}
\hline & \multicolumn{2}{|l|}{ A } & \multirow{2}{*}{$\begin{array}{l}\text { B } \\
\text { Mean } \pm \text { SD }\end{array}$} \\
\hline & Mean \pm SD of contralateral leg & Mean \pm SD of operated leg & \\
\hline LENGHT of STRIDE norm. for subject height & $0.85( \pm 0.07)$ & $0.83( \pm 0.06)^{*}$ & $0.95( \pm 0.31)$ \\
\hline CADENCE (steps/min) & $115.5( \pm 11.4)^{*}$ & $110.88( \pm 10.32)$ & $109.25( \pm 8.39)$ \\
\hline LENGTH of STEP norm. for subject height & $0.34( \pm 0.14)^{*}$ & $0.49( \pm 0.13)$ & $0.42( \pm 0.09)$ \\
\hline STANCE DURATION (\% of gait cycle) & $60.7( \pm 2.2)$ & $59.5( \pm 2.3)$ & $59.59( \pm 2.71)$ \\
\hline INITIAL DOUBLE STANCE DURATION (\% of gait cycle) & $10.6( \pm 2.1)$ & $9.6( \pm 1.8)^{*}$ & $9.37( \pm 1.69)$ \\
\hline TERMINAL DOUBLE STANCE DURATION (\% of gait cycle) & $9.7( \pm 2.2)$ & $10.4( \pm 2.2)$ & $10.79( \pm 1.64)$ \\
\hline PROGRESSION SPEED $(\mathrm{m} / \mathrm{s})$ & $0.82( \pm 0.12)$ & $0.78( \pm 0.11)^{*}$ & $1.35( \pm 0.17)$ \\
\hline
\end{tabular}

sions and rehabilitation treatments. All patients in group A were subjected to the same treatments of functional re-education and did not present post-operative complications. Patients were monitored on postoperative days $3,7,14$, and on follow-up examination after 1 month and 6 months. We excluded all patients with comorbidities or surgical complications.

Tests were proposed to the patients at least 24 months after surgery.

Institutional review board approval was obtained. All patients signed an informed consent form to be included in the study.

\section{Tests}

Subjects were required to perform three different motor tasks:

1. Brisk walking to a metronome $(1.6 \mathrm{~m} / \mathrm{s})$

2. Static loading with eyes open and eyes closed for 60 seconds

3. Heel rise on a $10^{\circ}$ inclined ramp.

The patients performed the first motor task several times and measurements were recorded. A minimum of three trials were then processed as described below. Postural stability was assessed for each eye-condition and a one-leg heel rise test was recorded for each leg.

Each patient was required to walk on a walkway $11.4 \mathrm{~m}$ long with two force plates (BERTEC) in the centre to measure ground-reaction forces. An optoelectronic stereometric system (ELITE BTS Milano) was used to obtain marker trajectories positioned on anatomical landmarks with the aid of an electromyographic recording system (PocketEMG, BTS Engineering, Milano) to maintain the surface electromyographic signal (sEMG).

The tests and corresponding measurements were conducted in the Movement Analysis Laboratory of the Marche Polytechnic University.

\section{Motor task description}

Gait: Each subject was required to walk barefoot on the walkway following the rhythm of a metronome. Each subject performed the tasks several times before reaching a repeatable cadence. We evaluated the adequate distance of foot impact from the force plates during these first trials and used them as a starting point. The patients were blinded to test indications to avoid bias. Several gait trials were then performed and recorded.
Posture: each subject was required to stand with both feet on a force plate in an upright position for $60 \mathrm{~s}$ performing one test with eyes open and one test with eyes closed. Measurements were recorded as described below.

One-leg Heel rise: the patient in upright position on an inclined plane $\left(10^{\circ}\right)$ was required to rise his/her heel keeping the other leg off the ground. The number of heel rises was free and dependent only on the subject's performance. For each leg only one trial was performed.

Parameters calculated (Data analysis): Anthropometric data, such as height, weight and heart rate at rest and at the end of the experimental session were measured during each session.

During each motor task, the following measurements were taken:

- three components of Ground Reaction Force (GRF) and the centre of pressure trajectory (COP);

- the trajectories of the markers positioned on the foot, leg, thigh and trunk as indicated by the DAVIS protocol [12].

- the electromyographic signal of the medial gastrocnemius (GAM), the anterior tibial muscle (TA) of both limbs, and the soleus muscle (SOL) of the contralateral limb. The investigators analysed the possible effect of the surgical treatment on motor coordination in relation to these muscles and to suggest the changing role of muscle control in dorsi-plantar flexion.

For each motor task, the following parameters were set:

1. Gait - flexion/extension angles of ankles, knees and hips, stride and step length, cadence, stance and swing duration, speed of progression. The asymmetry index, calculated for each parameter, was used to quantify the differences between the treated leg and the contralateral leg [13].

2. Posture: CoP parameters, such as medio-lateral and antero-posterior excursion, sway path, mean velocity and mean distance, as described in Prieto [14];

3. Heel rise- the number of rises, the height and the angle of foot described by maximum, minimum and mean values. The EMG signal was processed, and median frequency was calculated as an indication of possible muscular fatigue.

Moreover, the mean and standard deviations of each parameter during the three trials were calculated. 
- Table 3 Asymmetry in some spatio-temporal and dynamic parameters for Group A (9 subjects). If Asymmetry Index (ASI) is above 13, symmetry is considered critical.

\begin{tabular}{|l|l|}
\hline & $\begin{array}{l}\mathbf{N}^{\circ} \text { of patients with } \\
\text { ASI } 13 / \text { total number } \\
\text { of patients }\end{array}$ \\
\hline LENGHT of STEP & $9 / 9$ \\
\hline INITIAL DOUBLE STANCE DURATION & $5 / 9$ \\
\hline TERMINAL DOUBLE STANCE DURATION & $7 / 9$ \\
\hline F1 & $5 / 9$ \\
\hline F3 & $7 / 9$ \\
\hline T1 & $7 / 9$ \\
\hline T5 & $5 / 9$ \\
\hline
\end{tabular}

The Kolmogorov-Smirmov test (K-S test) was used to compare Group A to B. Levels of $p<0.05$ were significant.

\section{Results}

\section{Gait Analysis}

The spatio-temporal gait parameters ( $\triangleright$ Tab. 2 ) revealed inter-limb and intra-group differences. We observed a shorter step length in the contralateral leg compared to the operated limb, which was also significantly shorter compared to the controls $(p<0.05)$. The step cadence, calculated as the number of steps in one minute, was significantly greater $(p<0.05)$ in this group. This is most likely due to the reduction of the step length for the healthy leg of this group of patients. The initial double support phase was shorter than the terminal double support phase for the operated leg.

Progression speed was generally reduced in relation to the other group and was significantly reduced in the treated leg in relation to the controls $(p<0.05)$.

Asymmetry was present in all the above-mentioned parameters (step length, initial and terminal double support phase) as revealed by the asymmetry index for more than five patients $>$ Tab. 3 ).

Parameters obtained from the GRF trajectories showed differences. The patients bore less weight on the foot of the treated leg than on the contralateral leg ( $\triangleright$ Tab.4) during the loading phase $\left(F_{1}\right)$ and during the push off phase $\left(F_{3}\right)$. These measurements may have differed according to the asymmetry index for these parameters ( $\triangleright$ Tab. 3), that scored above the critical mean value (15) for five and respectively, seven of nine patients. With respect to the controls, patients increased (significantly, $p<0.05$ ) the peak load force phase of the contralateral leg and reduced (significantly, $p<0.05$ ) the peak load force during the push-off phase of the treated leg. The duration of the loading response phase, when impact absorption usually occurs, was significantly $(p<0.05)$ shorter in the operated leg compared to the control group ( $T_{1}$ in $\triangleright$ Tab. 4 and $\triangleright$ Fig. 2a). The stance phase in the anterior direction occurred moderately earlier compared to controls (see $T_{5} \triangleright$ Tab. 4 and $>$ Fig. 2 b).

In the kinematic analysis of the hip-knee-ankle angles, the dorsi-plantar flexion angle on the operated side was not within the normal range observed in the control population.
- Table 4 Mean and standard deviation values of dynamic parameters for each group of subjects (A: treated with soleus flap; B: control group).

\begin{tabular}{|l|l|l|l|}
\hline & A & Mean \pm SD of \\
contralateral leg & $\begin{array}{l}\text { Mean } \pm \text { SD of } \\
\text { operated leg }\end{array}$ & Mean \pm SD \\
\hline $\mathrm{F}_{1}(\mathrm{~N} / \mathrm{kg})$ & $12,2( \pm 1,2)^{*}$ & $11,5( \pm 1,5)$ & $11,3( \pm 1,0)$ \\
\hline $\mathrm{F}_{2}(\mathrm{~N} / \mathrm{kg})$ & $6,7( \pm 0,7)$ & $6,8( \pm 0,9)$ & $6,7( \pm 0,9)$ \\
\hline $\mathrm{F}_{3}(\mathrm{~N} / \mathrm{kg})$ & $11,6( \pm 1,2)$ & $10,3( \pm 0,8)^{*}$ & $11,3( \pm 0,9)$ \\
\hline $\mathrm{F}_{4}(\mathrm{~N} / \mathrm{kg})$ & $0,3( \pm 0,2)$ & $0,4( \pm 0,2)$ & $0,4( \pm 0,3)$ \\
\hline $\mathrm{F}_{5}(\mathrm{~N} / \mathrm{kg})$ & $-2,3( \pm 0,3)$ & $-2,2( \pm 0,6)$ & $-2,2( \pm 0,4)$ \\
\hline $\mathrm{F}_{6}(\mathrm{~N} / \mathrm{kg})$ & $2,2( \pm 0,6)$ & $2,1( \pm 0,4)$ & $2,2( \pm 0,3)$ \\
\hline $\begin{array}{l}\mathrm{T}_{1}(\% \mathrm{stance} \\
\text { phase })\end{array}$ & $22,2( \pm 5,4)^{*}$ & $19,6( \pm 5,1)^{*}$ & $22,5( \pm 3,1)$ \\
\hline $\begin{array}{l}\mathrm{T}_{2}(\% \text { stance } \\
\text { phase })\end{array}$ & $47,6( \pm 3,8)$ & $46,5( \pm 5,4)$ & $48,4( \pm 4,5)$ \\
\hline $\begin{array}{l}\mathrm{T}_{3}(\% \text { stance } \\
\text { phase) }\end{array}$ & $78,5( \pm 7,0)$ & $77,5( \pm 3,9)$ & $80,2( \pm 2,2)$ \\
\hline $\begin{array}{l}\mathrm{T}_{4}(\% \text { stance } \\
\text { phase })\end{array}$ & $1,9( \pm 1,2)$ & $2,5( \pm 1,5)$ & $3,6( \pm 9,2)$ \\
\hline $\begin{array}{l}\mathrm{T}_{5}(\% \text { stance } \\
\text { phase })\end{array}$ & $16,8( \pm 7,1)$ & $14,9( \pm 3,3)$ & $17,1( \pm 2,8)$ \\
\hline $\begin{array}{l}\mathrm{T}_{6}(\% \text { stance } \\
\text { phase })\end{array}$ & $88,9( \pm 3,7)$ & $87,7( \pm 2,7)$ & $88,1( \pm 1,8)$ \\
\hline
\end{tabular}

Peak F1 to F3 are related to the vertical component of Ground Reaction Forces (GRF) while peaks F4 to F6 are related to the anterior-posterior component of GRF. T1 to T6 are the time instants related to the force peaks, expressed as percentage of stance duration. * Statistical differences (K-S -test, $\mathrm{p}<0,05)$ between parameters of $A$ and $B$ group.

In all patients treated with the soleus flap, the ankle on the operated side presented mild deficit in the initial stance phase. The mean trends showed that the initial plantar flexion was absent with the ankle blocked in dorsi-flexion up to approximately $20 \%$ of the gait cycle. Subsequently, the plantar flexed from $20 \%$ to $65 \%$ of the gait cycle (in > Fig. 3, the gait trials were related to one patient in the group). Dorsiflexion was then present up to $100 \%$.

No statistical differences were observed between muscular activation timing of muscles in both legs and the behaviour of muscles in the control group. We compared both legs and noted that the anterior tibialis muscle of the treated leg prolonged its activation at the beginning of the stance phase while the medial gastrocnemius muscle anticipated activation.

\section{Posture}

The medio-lateral excursion of CoP in Open Eye (OE) and Closed Eye $(C E)$ condition was significantly $(p<0.05)$ lower than in the controls (OE: $9.7 \mathrm{~mm}$ with respect to $12 \mathrm{~mm}$; $\mathrm{CE}: 8.8 \mathrm{~mm}$ with respect to $13.7 \mathrm{~mm}$, > Tab.5). 

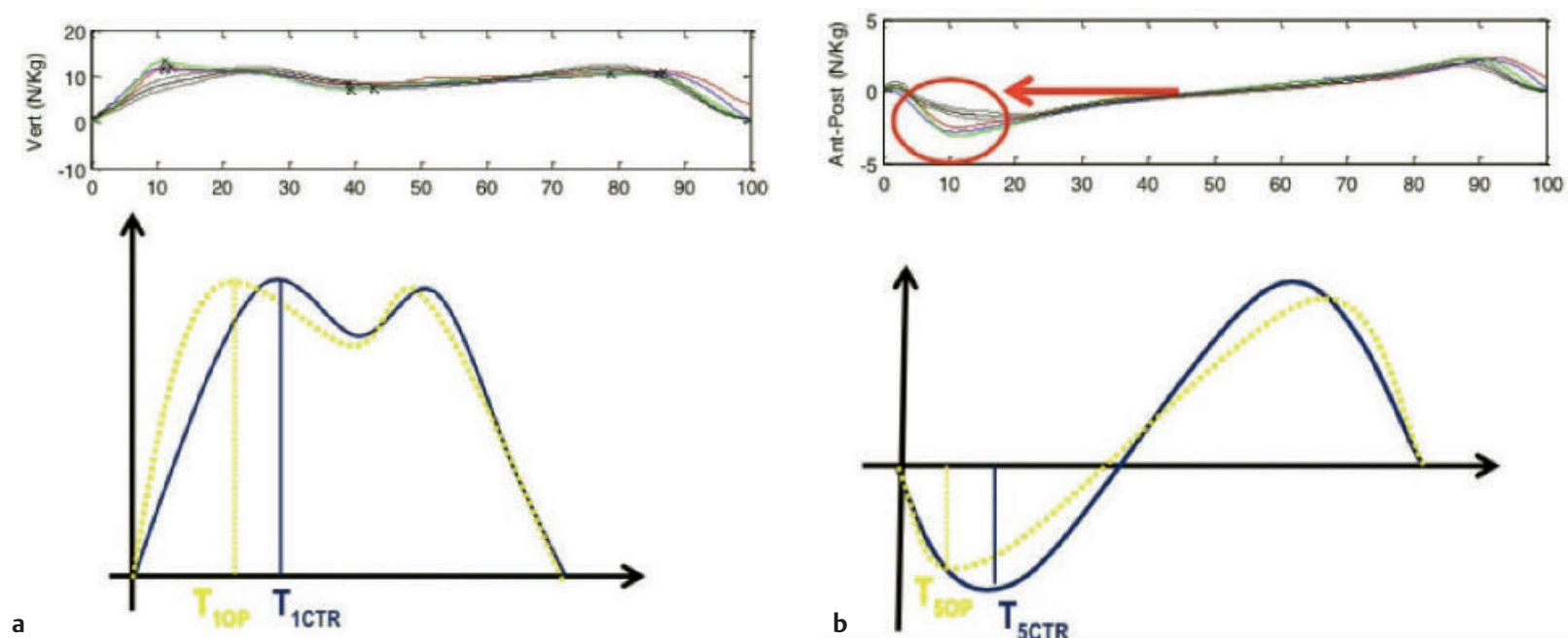

a

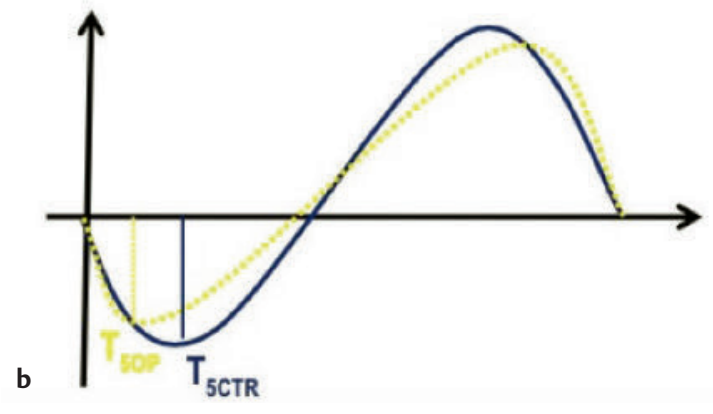

- Fig. 2 Dynamic parameters of gait; a vertical force component; $\mathbf{b}$ antero-posterior component

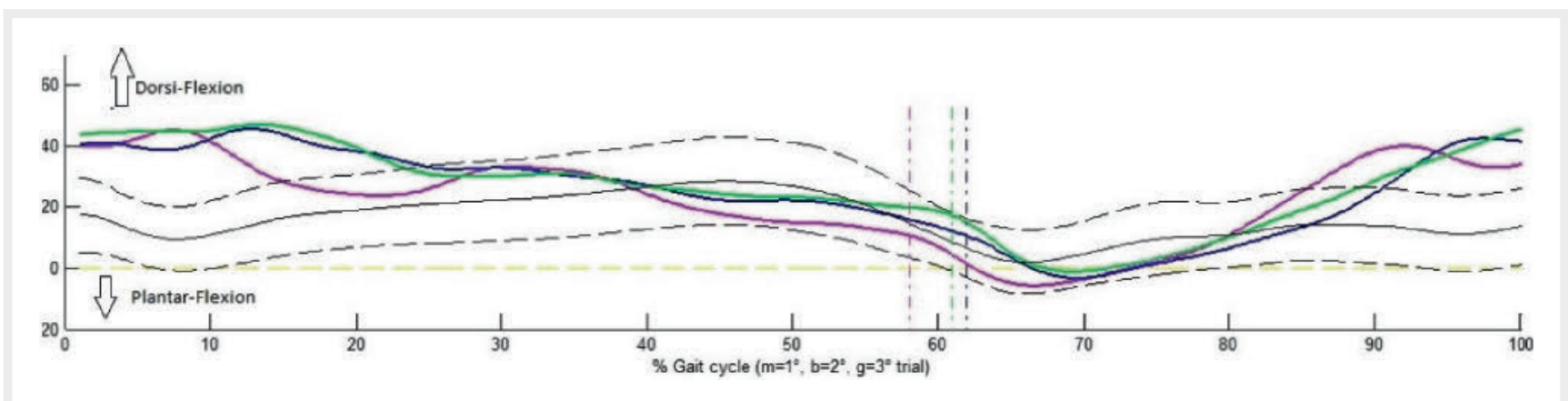

- Fig. 3 Trend of the angles of the ankle joints in patients reconstructed with a soleus muscle flap

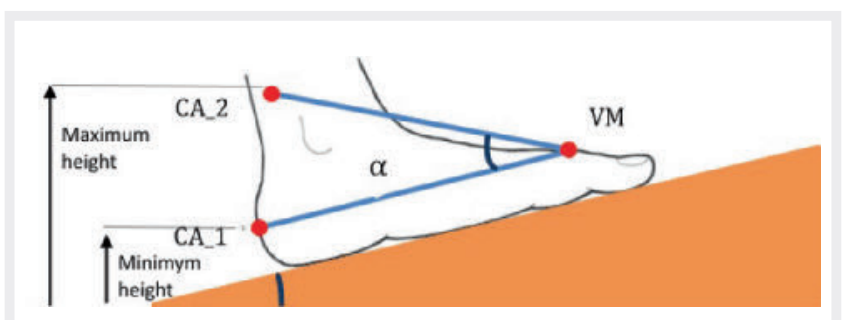

-Fig. 4 Foot during the Heel Rise Test; CA_1: the marker of the heel in the starting position; VM: the marker on the head of the fifth metatarsal; CA_2: the marker on the calcaneus in the position of heel lift. $\alpha$ : the angle that is formed between CA_1-VM and CA_2 -VM.

\section{Heel Rise}

The Heel rise was the motor task in which significant differences emerged among the groups ( $\triangleright$ Tab. 6 ).

The patients treated with the soleus flap performed a smaller number of rises than the controls both with the treated and the contralateral leg (15: treated, 25: contralateral, 29: control group).
The differences between legs in the number of rises was 10 , and 14 differences between the operated leg and Group B. The heel-rise height was measured by the vertical displacement of the marker positioned on the heel. At each heel rise, the foot movement, represented by the line connecting the heel and the fifth metatarsal head, was further defined by the angle $\alpha$, where the vertex was on the fifth metatarsal head ( $\triangleright$ Fig. 4). Both parameters were measured by their maximum, minimum and mean values. Each parameter scored lower for the treated leg than for the contralateral leg. Statistically significant differences $(p<0.05)$ were observed in all parameters for the treated leg, with the exception of mean height ( $\triangleright$ Tab.6). During the test the mean angle gradually reduced, and the minimum height increased at each rise. In fact, the patients avoided placing their foot on the ramp floor after each lift with foot raised from the ground by performing small oscillations.

To analyse the effect of missing soleus functionality, authors extracted the Mean Power Frequency (MPF) from the electromyographic signal. The MPF is, considered a relevant indicator of muscular fatigue. Four rises were identified during each rise test performed by each leg: one at start point (at approximately $10 \%$ of the entire duration of the test), two intermediate (at approxi- 
- Table 5 Postural parameters (mean and \pm standard deviation) as described in Prieto for the groups of subjects (A: treated with soleus flap; B: control group) during trials with open eyes (OE) and closed eyes (CE).

\begin{tabular}{|c|c|c|c|c|}
\hline & \multicolumn{2}{|l|}{ Group A } & \multicolumn{2}{|l|}{ Group B } \\
\hline & $\mathrm{OE}$ & CE & $\mathrm{OE}$ & CE \\
\hline $\begin{array}{l}\text { Max Esc.COP } \\
\operatorname{AP}(m m)\end{array}$ & $\begin{array}{l}21.4 \\
( \pm 7.2)\end{array}$ & $\begin{array}{l}26.1 \\
( \pm 9.7)\end{array}$ & $\begin{array}{l}21.3 \\
( \pm 10.2)\end{array}$ & $\begin{array}{l}23.8 \\
( \pm 5.2)\end{array}$ \\
\hline $\begin{array}{l}\text { Max Esc.COP } \\
\text { ML(mm) }\end{array}$ & $\begin{array}{l}9.7 \\
( \pm 3.7)^{*}\end{array}$ & $\begin{array}{l}8.8 \\
( \pm 3.5)^{*}\end{array}$ & $\begin{array}{l}12.0 \\
( \pm 8.5)\end{array}$ & $\begin{array}{l}13.7 \\
( \pm 7.5)\end{array}$ \\
\hline MDIST (mm) & $4.4( \pm 1.6)$ & $4.9( \pm 1.8)$ & $\begin{array}{l}4.4 \\
( \pm 1.9)\end{array}$ & $\begin{array}{l}5.3 \\
( \pm 1.7)\end{array}$ \\
\hline Sway Path (mm) & $\begin{array}{l}180.5 \\
( \pm 26.9)\end{array}$ & $\begin{array}{l}242.7 \\
( \pm 60.2)\end{array}$ & $\begin{array}{l}203.7 \\
( \pm 103.2)\end{array}$ & $\begin{array}{l}247.0 \\
( \pm 95.5)\end{array}$ \\
\hline $\mathrm{MV}(\mathrm{mm} / \mathrm{s})$ & $9.0( \pm 1.3)$ & $12( \pm 3.0)$ & $\begin{array}{l}10.2 \\
( \pm 5.2)\end{array}$ & $\begin{array}{l}12.4 \\
( \pm 4.8)\end{array}$ \\
\hline
\end{tabular}

* Statistical differences (K-S -test. $\mathrm{p}<0.05)$ between parameters of $\mathrm{A}$ and $B$ group.

Max Esc.COP AP/ML: maximum excursion of Center of Pressure in antero-posterior/medio-lateral direction; MDIST: mean distance; MV: mean velocity;

mately $40 \%$ and $60 \%$ of the entire duration of the test), and a final rise (at approximately $90 \%$ of the entire duration of the test). In healthy subjects, the MPF initially indicated a sharp fall and subsequently decreased for the tibialis anterior and gastrocnemius ( Fig. 5) but remained constant for the soleus. The MPF obtained by two muscles of the treated leg (Tibialis Anterior and Medial Gastrocnemius) remained steady or slightly decreasing for both muscles (red and green line, > Fig. 6a). In the tests performed by the contralateral leg, the MPF decreased for the tibialis anterior and the medial gastrocnemius muscle (red and green line, > Fig. $6 \mathbf{b}$ ). The MPF for the soleus decreased up to $60 \%$ then, remained steady or moderately increased towards the final stage of the trial (yellow line, > Fig. 6b).

\section{Discussion}

Many authors have reported success in the use of the soleus flap as coverage after trauma of the soft tissues of the leg but have neglected to examine the functional deficit resulting from the removal of the monoarticular end of the triceps surae [11].

The aim of this study was to assess potential signs of "disability" in patients treated with soleus flap, comparing them with a healthy subject population. Moreover, the authors investigated the likelihood of treatment-related deficit and possible mechanisms of adaptation.

\section{Gait Analysis}

Kramers-de Quervain et al. showed [10] the substantial recovery of gait function after surgical treatment in this type of patient. The authors reported differences in the terminal phase of stance during fast gait compared to the controls [10], observing critical points in the propulsion phase for the treated leg which was characterised
- Table 6 Mean and standard deviation of some parameters used to characterise Heel rise test for two group of subjects (A: treated with soleus flap; B: control group). * Statistical differences (K-S -test, $p<0,05)$ between parameters of $A$ and $B$ group.

\begin{tabular}{|c|c|c|c|}
\hline & \multicolumn{2}{|l|}{ Group A } & \multirow[t]{2}{*}{ Group B } \\
\hline & $\begin{array}{l}\text { Contralat. } \\
\text { Leg }\end{array}$ & $\begin{array}{l}\text { Operated } \\
\text { Leg }\end{array}$ & \\
\hline Number of rises & $25( \pm 12,1)$ & $15( \pm 4,5)^{*}$ & $29( \pm 13)$ \\
\hline $\begin{array}{l}\text { Maximum height } \\
(\mathrm{cm})\end{array}$ & $9,5( \pm 2,8)$ & $5,6( \pm 2,8)^{*}$ & $11,6( \pm 4)$ \\
\hline $\begin{array}{l}\text { Minimum height } \\
(\mathrm{cm})\end{array}$ & $5,4( \pm 2,9)$ & $2,5( \pm 2,1)^{*}$ & $4,3( \pm 1,2)$ \\
\hline Mean height (cm) & $7,1( \pm 2,5)$ & $4,0( \pm 2,3)$ & $8,8( \pm 0,5)$ \\
\hline Maximum angle $\left({ }^{\circ}\right)$ & $40,0( \pm 16,6)$ & $20,1( \pm 11,1)^{*}$ & $44,6( \pm 1,8)$ \\
\hline Minimum angle $\left({ }^{\circ}\right)$ & $11,9( \pm 4,1)^{*}$ & $6,3( \pm 3,8)^{*}$ & $18,3( \pm 0,6)$ \\
\hline Mean angle $\left({ }^{\circ}\right)$ & $21,8( \pm 6,8)$ & $11,6( \pm 6,5)^{*}$ & $29,5( \pm 0,5)$ \\
\hline $\begin{array}{l}\text { Differences between } \\
\text { limb's rises }\end{array}$ & \multicolumn{2}{|l|}{10} & \\
\hline
\end{tabular}

by a lower peak of force. Our data in gait confirmed these findings with a reduced vertical peak of force $\left(\mathrm{F}_{3}\right)$ in the operated leg during fast gait and propulsion phase. In our study the loading phase of the treated leg was characterised by an earlier $\left(T_{1}\right)$ and low peak $\left(F_{1}\right)$ in relation to the contralateral leg, further confirmed by a reduced initial double support phase duration ( $\triangleright$ Tab. 2). These results show the patient's tendency to decrease the duration of the body weight-transfer phase from the contralateral to the operated leg and to anticipate a more comfortable and stable position of the foot flat on the ground.

To compare data with Kramers-de Quervain and co-authors' results [10], in this study, the patients were not required to walk at a self-selected fast pace but at a predetermined cadence to a metronome. Group A patients failed to achieve the predicted walking speed, performing at a slower speed rate compared to the other groups. The reduced step length was also relevant for the contralateral leg, in relation to the treated leg and the control group. This reduction may be due to the subjects avoiding excessive forward displacement of the body on the treated leg. In this phase, in fact, a greater forward displacement of the contralateral leg could produce the raising of the heel of the treated leg considering the triceps surae activity.

The angular kinematics of the ankle was compromised with reduced and uncertain dorsi-plantar flexion due to the initial trauma rather than to the surgical treatment. No significant differences were observed during gait on muscular activation timing with respect to the control group. Patients in Group A presented a prolonged muscular activity of the tibialis anterior and gastrocnemius during stance of the treated leg in relation to the contralateral leg. The authors suggest that this outcome may be related to the patient's tendency to accurately control the body weight transfer phase and the subsequent mid-stance phase on the treated leg. Walking and brisk walking do not require substantial changes in muscular control, and the soleus function is commonly well-developed by the other triceps surae muscles. 


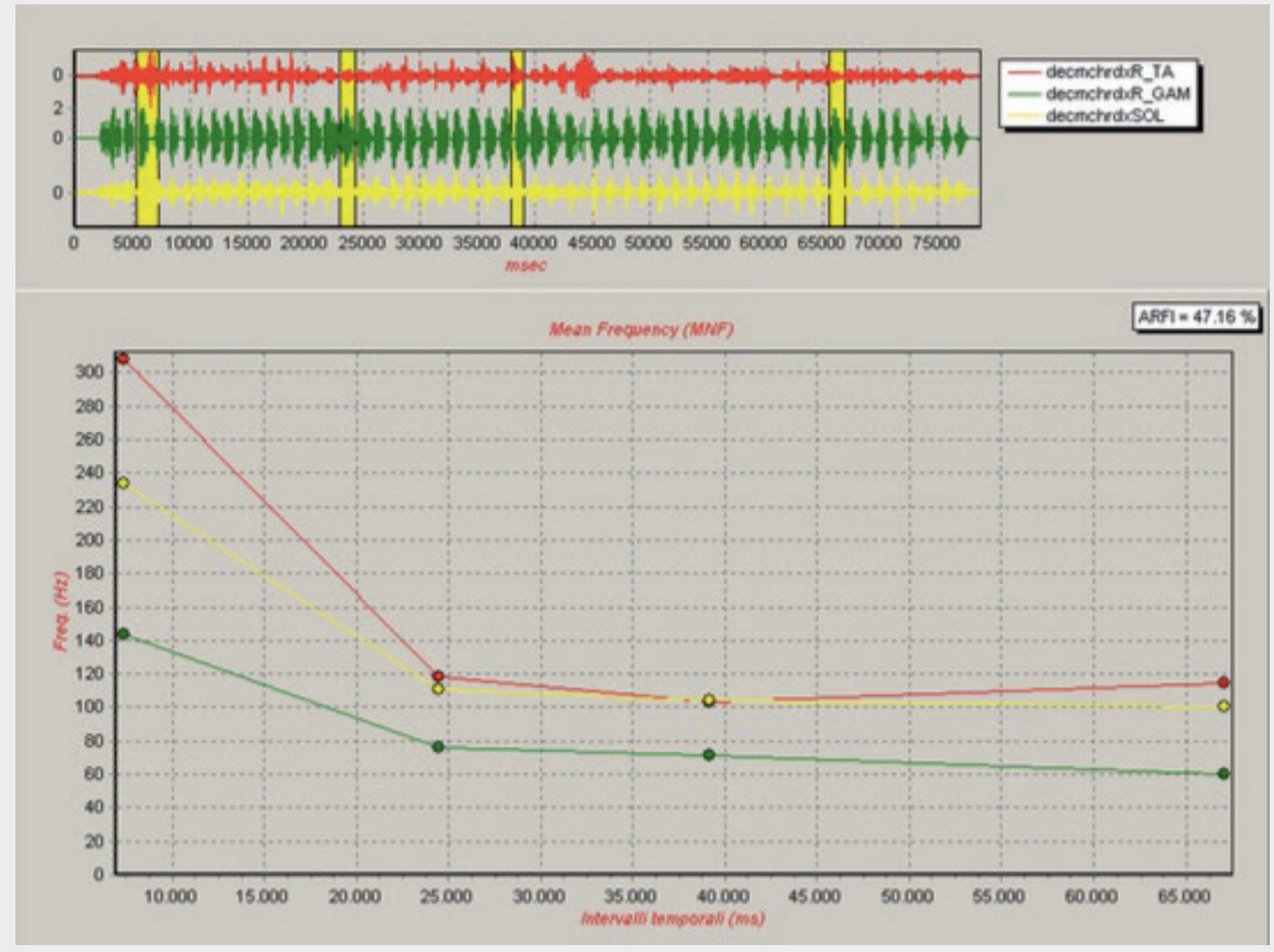

-Fig. 5 Electromyographic data of anterior Tibial, Gastrocnemius and Soleus muscle in a patient of Group B.

\section{Posture}

The soleus muscle plays a relevant role in posture, with regards to its histological characteristics. It has a dominant role in antero-posterior excursion of the centre of mass during prolonged posture over time [15]. The recordings of postural centre of pressure $(\mathrm{CoP})$ reveal that the erect position is not stationary. On both the planes (sagittal and frontal) there is a slow but continuous shifting of the body weight on the two limbs. In normal conditions, the parameters that describe the CoP excursion show elevated values in the test with closed eyes (CE) compared to the test with open eyes $(\mathrm{OE})$ which is a characteristic of the sensory system channel in eyes closed and elimination of the visual channel which would result in increased swing movement. In this study, the medio-lateral excursion parameter of the $\mathrm{OC}$ and CE tests yielded significantly smaller parameter values in subjects treated with soleus flap compared with controls. This outcome is most likely due to pathological subjects undertaking this exercise with greater articular stiffness, especially at the level of the tibiotarsal joint. Results obtained for both the pathological groups in both the posture tests revealed the absence of relevant effects due to the loss of soleus functionality. Conversely, certain CoP parameters highlighted trauma-related effects common to both groups.

\section{Heel Rise}

Literature reports the relevance of the "heel rise test" in detecting deficits at the level of the triceps surae $[14,16,17]$. A patient was on an inclined plane $\left(10^{\circ}\right)$ and was requested to rise his/her heel until he/she felt comfortable, maintaining the contralateral foot raised from the ground. After each rise, the patient was required to replace the foot on the plane and to repeat the rising movements many times until tired. A trial for each leg was performed and processed. The heel rise test is commonly performed to verify the efficiency of the triceps surae [16]. It can be performed on an inclined plane or a flat surface. The number of heel rises performed by the patient was considered as an indicator of an efficient triceps surae functionality. The exercise of standing on the toes assesses resistance rather than muscle power [17]. The repetitions may induce muscular fatigue of the triceps surae; thus, the role played by the soleus muscle in conditions of fatigue resistance is relevant and may be analysed in detail using this kind of test. The soleus is mainly made up of type I fibres and will engage in prolonged activities over time.

Lunsford and Perry suggested 20 heel rises as an acceptable number to consider as a "normal" performance achievement. [18]

In this study, authors examined the performance of each leg to assess whether the loss of soleus functionality could engender deficit during movement. Authors adopted a more challenging setting where patients were required to initiate movement with stretched 

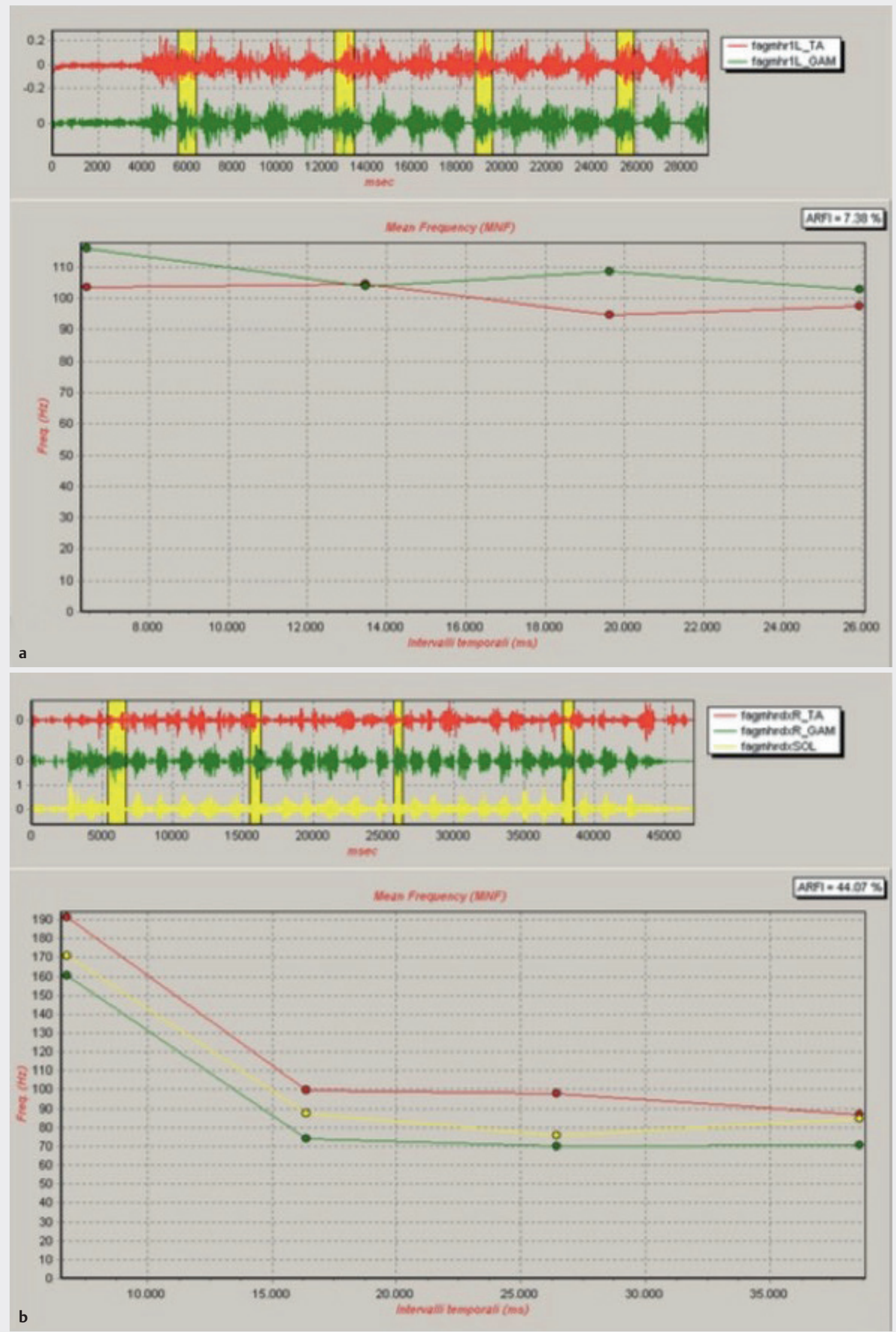

- Fig. 6 a, b Electromyographic data of anterior Tibial, Gastrocnemius and Soleus muscle in a patient of Group A. 
calf muscles, using a ramp with an inclination of $10^{\circ}$ to stress the ankle starting from a dorsi-flexed position.

The outcomes herein, demonstrated that the patients involved in the heel rise test, succeeded in performing the motor task. The patients who had undergone reconstruction with a soleus flap performed a significantly lower number of heel rises than the control group, and the number of heel rises differed between the operated and the contralateral leg. For the operated leg of patients belonging to Group A, the mean number of heel rises was 14 less than the expected value (20); in addition, the height of the rise and the angular excursion were smaller than in the controls.

We therefore indicate that patients with intact triceps surae and without deficit at muscular level have a resistance to fatigue comparable with that of healthy subjects.

The lower values in heel rise height may be due to the blocking of the ankle as a result of the trauma.

Previous investigations reported a constant mean power frequency (MPF) during heel rise in the soleus muscle only, in relation to muscular fatigue with a decrease of MPF in the gastrocnemius muscle [17].

The trend of the MPF observed in the control group and Group A in relation to the contralateral leg revealed that heel-rise fatigue was supported by the reduction of this parameter for the anterior tibial and medial gastrocnemius muscle. The soleus and its characteristic muscular fibres, is a muscle suited to resistance and initially presented a fall and subsequent steady MPF trend. The patients with soleus flap treatment successfully performed the heel rises owing to the functionality of the remaining muscles. The MPF relative to both muscles did not show an evident reduction but was generally constant, suggesting that gastrocnemius also compensated for the absence of the soleus in tasks that required fatigue resistance. Nevertheless, it is clear that, considering the small number of heel rises performed with the treated limb by the patients of the group $A$, the residual triceps surae does not completely atone for the lack of soleus functionality, therefore suggesting that adaptation of the muscle fibres is not sufficient to compensate for the lack of muscular resistance.

\section{Limitations of the study}

This study has some limitations. Although all traumas were classified as type III B according to the Gustilo-Anderson classification, the involvement of more or less large bone areas and the diverse initial soft tissue extension could influence the assessment of deficits during motor tasks (gait, posture and heel rise test).

Another limitation of the study is the use of the free fibula flap taken from the contralateral limb to reconstruct the traumatised tibia. As reported by some authors, no significant differences were found in gait parameters in Pre-post surgical gait analysis comparison of patients who had undergone an osteocutaneous free fibula transfer $[19,21]$. These studies confirm that the evaluation of gait is not significantly influenced by the concomitant use of a fibula flap, but could lead to assessment bias of the motor function in the traumatised limb and in the donor limb.

The retrospective design and the small sample population were another limitations of the study. Larger sample case series with long term follow-up are needed to validate the results.

\section{CONCLUSIONS}

Our findings report that the patients with detached soleus muscle as a coverage completely regained the ability to walk autonomously albeit presenting difficulties in increasing walking speed.

The patients who had undergone reconstruction with a soleus flap reported pain in the operated area and reduced mobility of the tibiotarsal joint.

Gait analysis is a standard exercise in the field of movement analysis, but herein, did not clarify the attribution of the deficits in relation to the type of reconstruction or to the extent of the trauma.

With reference to Kramers-de Quervain et al., we conducted the heel rise test, which allowed better identification of soleus performance in relation to the other muscles of the triceps surae. We consider the heel rise test as an improved assessment measurement to distinguish between the effect of the surgical treatment and the effect of the trauma, providing quantifiable indicators of the deficit associated to the use of the soleus. Our findings suggest that an identical measure of reduced trauma-related mobility in the ankle, and lack of the soleus muscle may lead to further deficits in the operated limb at muscular level.

\section{Conflict of interest}

The authors declare that they have no conflict of interest.

References

[1] Mathes S], Nahai F. Reconstructive Surgery: Principles, Anatomy \& Technique. New York: Churchill Livingstone; 1997

[2] Gustilo RB, Mendoza RM, Williams DN. Problems in the management of type III (severe) open fractures: a new classification of type III open fractures. J trauma 1984; 24: 742-746

[3] Gustilo RB, Merkow RL, Templeman D. The management of open fractures. J Bone Joint Surg Am 1990; 72: 299-304

[4] Martini R. Treand of the treatment of critical limb ischemia during the last two decades. Clin Hemorheol Microcirc 2018; 69: 447-456

[5] Engel $\mathrm{H}$, Hirche $\mathrm{C}$, Lehnhardt $\mathrm{M}$ et al. Aspects of microsurgical reconstruction for lower extremity defects. Handchir Mikrochir Plast Chir 2013; 45: 59-66

[6] Tu YK, Yen CY, Ma CH et al. Soft-tissue injury management and flap reconstruction for mangled lower extremities. Injury 2008; 39: 75-95

[7] Riccio M, Pangrazi PP, Campodonico A et al. Delayed microsurgical reconstruction of the extremities for complex soft-tissue injuries. Microsurgery 2005; 25: 272-283

[8] Godina M, Lister G. Early microsurgical reconstruction of complex trauma of the extremities. Plast Reconstr Surg 1986; 78: 285-292

[9] Heller L, Levin LS. Lower extremity microsurgical reconstruction. Plast Reconstr Surg 2001; 108: 1029 
[10] Kramers-de Quervain IA, Läuffer JM, Käch K et al. Functional donor site morbidity during level and uphill gait after a gastrocnemius or soleus muscle flap procedure. J Bone Joint Surg Am 2001; 83A: 239-246

[11] Beck JB, Stile F, Lineaweaver W. Reconsidering the soleus muscle flap for coverage of wounds of the distal third of the leg. Ann Plast Surg 2003; 50: 631-635

[12] Davis RB, Ounpuu S, Tyburski D] et al. A gait analysis data collection and reduction technique. Hum Mov Sci 1991; 10: 575-587

[13] Herzog W, Nigg BM, Read LJ et al. Asymmetries in ground reaction force patterns in normal human gait. Med Sci Sports Exerc 1989; 21: $110-114$

[14] Prieto TE, Myklebust JB, Hoffmann RG et al. Measures of postural steadiness: differences between healthy young and elderly adults. IEEE Trans Biomed Eng 1996; 43: 956-966

[15] Mochizuki G, Ivanova TD, Garland S]. Synchronization of motor units in human soleus muscle during standing postural tasks. J Neurophysiol 2005; 94: 62-69

[16] Österberg U, Svantesson U, Takahashi H et al. Torque, work and EMG development in a heel-rise test. Clin Biomec 1998; 13: 344-350

[17] Kasahara S, Ebata J, Takahashi M. Analysis of the repeted one-leg heelrise test of ankle plantar flexors in manual muscle testing. J Phys Ther Sci 2007; 19: 251-256

[18] Lunsford BR, Perry J. The standing Heel-rise test for ankle plantar flexion: criterion for normal. Phys Ter 1995; 75: 694-698

[19] Lee JH, Chung CY, Myoung H, Kim M], Yun PY. Gait analysis of dono leg after free fibular flap transfer. Int J Oral Maxillofac Surg 2008; 37 : 625-629

[20] Di Giuli R, Zago M, Beltramini GA et al. Donor-site morbidity after osteocutaneous free fibula transfer:longitudinal analysis of gait performance. J Oral Maxillofacial Surg 2019; 77: 648-657

[21] Chou SW, Liao HT, Yazar S et al. Assessment of fibula osteoseptocutaneous flap donor-site morbidity using balance and gait test. J Orthop Res 2009; 27: 555-560

[22] Maurer-Ertl W, Glehr M, Friesenbichler J et al. No adverse affect after harvesting of free fibula osteoseptocutaneous flaps on gait function. Microsurgery 2012; 32: 364-369

[23] Ferrari S, Perlangeli G, Mammi P et al. Bilateral harvesting of a fibula free flap: assessment of morbidity. J Craniofac Surg 2018; 29: 2131-2134 